\title{
INHALT
}

\section{EINFUHRUNG 9}

Der wenig erforschte Unbekannte Io

Fabulieren in Verspaaren und Antithesen $\quad$ I2

Klassische Flicken in der Fabeltextur Is

Produktives Fortwirken eines Missverstandenen 2I

Kodikologischer Irrgarten 24

Schlange im Haus statt am Busen 3I

Noch nicht in Konkurrenz mit Phaedrus und Aisopos 34

Neuland in einer Terra paene incognita 37

AVIANI FABULAE

AVIAN, FABELN 4I

ROMULI AESOPUS LATINUS

DER AESOPUS LATINUS DES ROMULUS 97

\section{ANHANG}

Zum lateinischen Text dieser Ausgabe 209

Erläuterungen 214

Bibliographie 230

Fabelindex 234 
